\title{
The invasive aquatic macrophyte Hydrilla verticillata facilitates the establishment of the invasive mussel Limnoperna fortunei in Neotropical reservoirs
}

\author{
Thaisa S. MICHELAN, ${ }^{*}$ Márcio J. SILVEIRA, Danielle K. PETSCH, Gisele D. PINHA, Sidinei M. THOMAZ \\ Universidade Estadual de Maringá, Departamento de Biologia, Nupelia, CEP 87020-900 Maringá, PR, Brazil \\ *Corresponding author: thaisamichelan@gmail.com
}

\begin{abstract}
The effects of introduced species on native species have been widely studied, however, invader-invader interactions are still poorly explored. Two non-native invasive species, the bivalve Limnoperna fortunei and the submersed macrophyte Hydrilla verticillata, have infested many aquatic ecosystems worldwide, and they are rapidly becoming nuisances in several water bodies in Brazil. We tested the hypothesis that $\mathrm{H}$. verticillata facilitates the establishment of $\mathrm{L}$. fortunei more than do native macrophytes. We surveyed mussels attached to two native macrophytes and to this invasive macrophyte in three Brazilian reservoirs and compared the length, density and biomass of the attached mussels relative to the host macrophyte species. All of the values of these attributes in $\mathrm{L}$. fortunei were higher in the mussels attached to $\mathrm{H}$. verticillata than in those attached to the native macrophytes. These results supported our initial hypothesis because the settlement of L. fortunei appeared to be facilitated by the invasive macrophyte, allowing higher abundances of the mussels as well as the more effective establishment of the mussel population. Various mechanisms could interact to facilitate the superior performance of $\mathrm{L}$. fortunei in the invasive plant. $\mathrm{H}$. verticillata is more flexible and withstands more mussels without breaking. Furthermore, this plant has different attached algae, which may be more beneficial for mussels. Thus, as a response to the facilitation suggested by our work, the mussel has greater opportunities to succeed in habitats colonised by the non-native H. verticillata. Although we have not evaluated the effects of this facilitation on aquatic communities or the ecosystem, our results could represent the first step of an invasional meltdown.
\end{abstract}

Key words: Co-occurrence, exotic species, Egeria najas; Egeria densa, positive interactions, non-native species.

Received: November 2013. Accepted: April 2014.

\section{INTRODUCTION}

Several studies have investigated the changes caused by non-native invasive species in native populations, communities and ecosystems (Clayton and Edwards, 2006; Thouvenot et al., 2012). Although several of these studies have found negative effects, caused by competition (Klein and Verlaque, 2009; Michelan et al., 2010; Vilà et al., 2011), others have found positive effects (Rodriguez, 2006; Altieri et al., 2010), such as facilitation of native species (Schlaepfer et al., 2011). As for invader-invader interactions, Green et al. (2011) have observed that they may have broad but still poorly explored consequences for invasion success, potentially affecting the evolution of species traits, the attributes of the recipient communities and propagule pressure.

Two non-native invasive species, the bivalve Limnoperna fortunei (Dunker, 1857), known as the golden mussel, and the submersed macrophyte Hydrilla verticillata L.f. Royle, commonly designated hydrilla, have infested many aquatic ecosystems worldwide and are becoming nuisances in several water bodies in Brazil (Sousa et al., 2009; Sousa, 2011). Limnoperna fortunei is native to Southeast Asia. It is a sessile freshwater mytilid mussel that forms aggregations (druses), and it has been introduced in other regions and has become troublesome (Ricciardi, 1998), especially in East Asia and North America (Ricciardi, 1998; Belz et al., 2012). In Brazil, it was first recorded in 1999 (Mansur et al., 1999, Takeda et al., 2003). This species attaches to hard or soft and natural or artificial substrata (Darrigran and Ezcurra de Drago, 2000; Karatayev et al., 2007), such as rock, plants, artificial plants, trunks, shells, piers, tubes and walls (Darrigran and Ezcurra de Drago, 2000; Karatayev et al., 2007; Burlakova et al., 2012). The second non-native species, $H$. verticillata, is a rooted-submersed aquatic macrophyte (family Hydrocharitaceae) native to Asia and many Pacific islands. It is now widespread throughout Australia as well as in scattered sites in Europe, South and North America and Africa (Cook and Lüönd, 1982; Madeira et al., 2007; Sousa, 2011). This species has recently been introduced in several aquatic ecosystems in the Neotropics (Sousa et al., 2009). Hydrilla verticillata can influence the morphology of freshwater ecosystems, increasing the physical complexity of the habitat. Because this species produces high biomass (Sousa et al., 2010), it competes intensively with native species. Hydrilla verticillata is morphologically similar to two native species (Egeria densa Planch. and Egeria najas Planch.; Becker et al., 
2007). However, both species co-occur side by side in several Brazilian reservoirs in the Paraná river basin (T.S. Michelan, personal observation).

Aquatic macrophytes play an important role in structuring habitats in several aquatic ecosystems. These plants vary in their level of complexity and include a variety of life forms that occur along depth gradients, providing habitat for aquatic organisms and consequently influencing the attributes of their associated assemblages. Several studies have focused on the relationship between the associated fauna and the structural complexity of macrophytes (Jeffries, 1993; Pelicice and Agostinho, 2006). However, no studies to date have focused on the preferences of $L$. fortunei for establishment on non-native or native species of macrophytes or on understanding the mechanisms that influence invasive macro-invertebrates' community diversity, structure, and abundance when attached to these macrophytes (Ritchie and Olff, 1999; Almany, 2004; Taniguchi and Tokeshi, 2004).

In view of the effects of invasive species on native communities, we conducted this study to investigate whether certain submersed aquatic macrophyte species (invasive or native) facilitate the occurrence of an invasive mussel species. We hypothesised that Hydrilla verticillata facilitates the establishment of Limnoperna fortunei more than do native macrophyte species. This hypothesis assumes that both $H$. verticillata and $L$. fortunei are native to the same region and, thus, share a common evolutionary history.

\section{METHODS}

\section{Sampling methods}

We sampled the aquatic macrophytes in three reservoirs located in several rivers of the Upper Paraná river basin (the Paranapanema, Tietê and Paraná rivers). The native macrophytes examined were E. densa/E. najas, and the non-native invasive was $H$. verticillata. We selected three independent sampling stations per reservoir (located at distances greater than approximately $4 \mathrm{~km}$ from each other). We chose places where at least two species (the non-native and one or two natives) occurred simultaneously and nearby. The three species co-occurred at three sampling stations, E. densa and $H$. verticillata co-occurred at four stations, and E. najas and H. verticillata cooccurred at two stations. Thus, $H$. verticillata co-occurred with at least one native species at all sampling stations.

To evaluate whether the invasive macrophyte $H$. verticillata facilitated the mussel more than did the natives, we sub-sampled five individuals (each approximately one meter in length) of each macrophyte, including one main stem and roots, at all sampling stations. The individuals were placed in a plastic bottle with $70 \%$ alcohol for sub- sequent screening of the L. fortunei and to measure the dry weight of the macrophytes.

In the laboratory, we separated individual $L$. fortunei from the plants under a stereoscopic microscope, and the following attributes of the mussel were measured: length $(\mathrm{cm})$, number of individuals and bivalve biomass per macrophyte biomass (dry weights - DW). We measured mussel length in randomly selected 20 individuals per sample station. The DWs of both bivalve and macrophyte were obtained after drying the material in an oven at $80^{\circ} \mathrm{C}$. Because we collected five fragments at each sampling station, the means of the variables above, obtained for all five plants, were considered replicates in the analyses.

\section{Data analysis}

We applied a Student's $t$-test for independent samples to evaluate differences in the attributes of $L$. fortunei (length, density and biomass of individuals per macrophyte DW) between invasive and native macrophytes. Because the three species did not co-occur at all sites, we grouped the results for both species of Egeria spp. for comparison with the results found in $H$. verticillata. Accordingly, our results expressed differences between the invasive species and the native macrophytes. The homoscedasticity of the data was tested using a Levene test. If this assumption was not satisfied by the data, we used a nonparametric Mann-Whitney U-test. We used the program STATISTICA 7.0 (StatSoft, Inc. 2007) to perform all analyses.

\section{RESULTS}

The plant biomass was, on average $2.04 \mathrm{~g}( \pm 0.39 \mathrm{SD})$ for $H$. verticillata and $2.41 \mathrm{~g}( \pm 0.40 \mathrm{SD})$ for Egeria spp and they are not different significantly from each other $(\mathrm{t}=-1.64, \mathrm{df}=19, \mathrm{P}=0.12$ ). All L. fortunei attributes (length, density and biomass per macrophyte DW) were higher for the bivalves colonising $H$. verticillata than for those attached to the native macrophyte species (Fig. 1).

The lengths of the mussels varied from 0.45 to $2.1 \mathrm{~cm}$, and the Student $\mathrm{t}$-test results showed that these lengths differed significantly between the invasive and native macrophyte species $(\mathrm{t}=6.88, \mathrm{df}=19, \mathrm{P}<0.001$; Fig. 1A). Hydrilla verticillata was the plant that showed the largest individuals of $L$. fortunei.

The mussel densities varied from 0 to 82.44 ind. $g$ $\mathrm{DW}^{-1}$, and the mussel biomass varied from 0 to $0.75 \mathrm{~g}$ $\mathrm{DW}^{-1}$. The invasive mussel's density and biomass were both significantly affected by the macrophyte species (Mann-Whitney test $-Z=3.77, \mathrm{P}<0.001$ and $Z=3.84$, $\mathrm{P}<0.001$; Fig. $1 \mathrm{~B}, \mathrm{C})$. The mean values of these two response variables were higher for the bivalves attached to $H$. verticillata than for those attached to the native macrophytes (Fig. 1 B,C). 


\section{DISCUSSION}

Our study showed that the values of all attributes (length, density and biomass of L. fortunei) were higher in the invasive macrophyte $(H$. verticillata) than in the na-
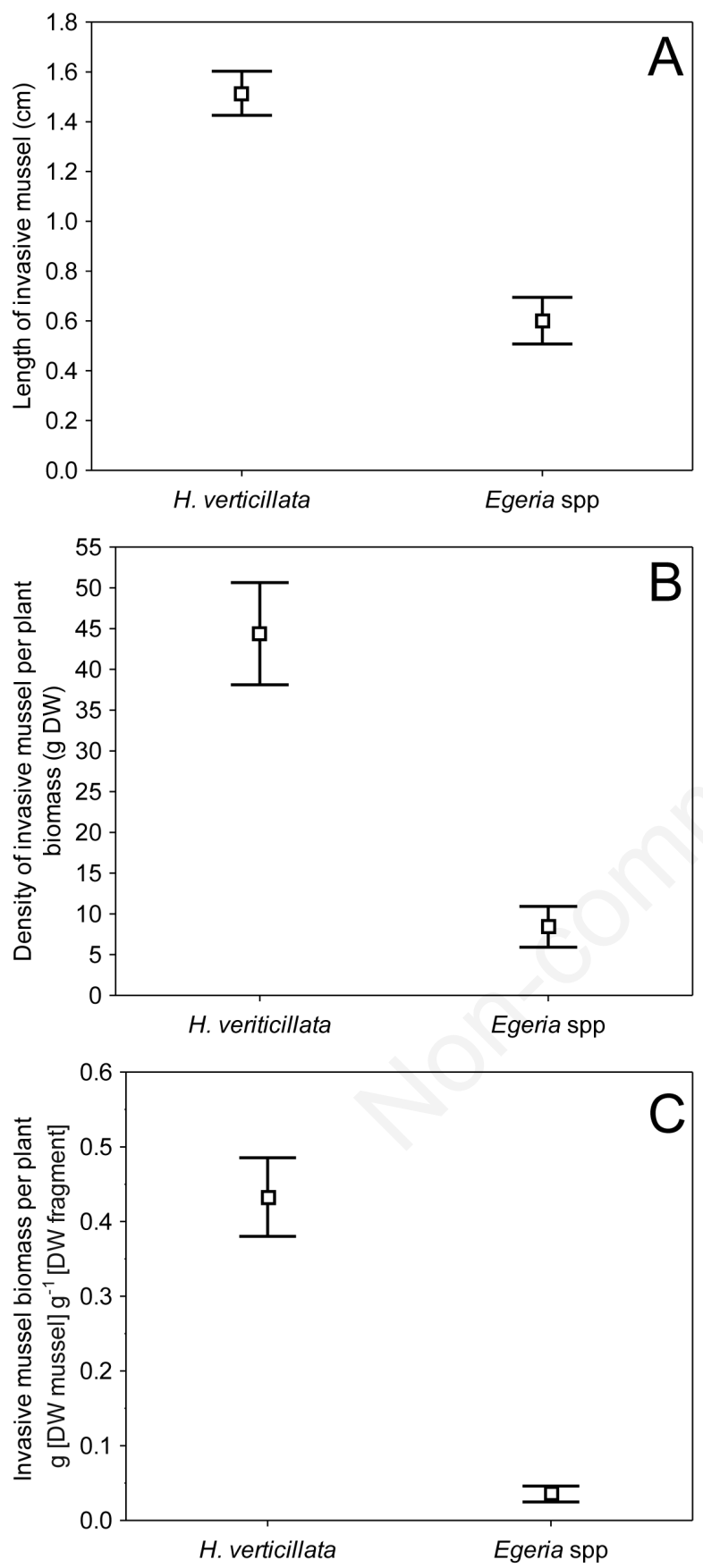

Fig. 1. Presence of Limnoperna fortunei in the macrophyte species Hydrilla verticillata (invasive - $\mathrm{N}=9$ ) and Egeria spp. (native - N=12). Limnoperna fortunei length (A), density (B, number of $L$. fortunei) and biomass $(\mathrm{C}$, biomass of $L$. fortunei) per unit macrophyte biomass. tive species (E. densa or E. najas). These results support our hypothesis that the settlement of $L$. fortunei is facilitated by the invasive macrophyte. Hydrilla verticillata supports higher abundances of the invasive mussels as well as more successful establishment of their populations, with larger individuals than those associated with native plants. Note that, although $H$. verticillata is one of the most extensively studied aquatic plants worldwide, knowledge about ecological processes involving this species is still lacking (Sousa, 2011). To our knowledge, the current study is the first to address the specific association between $H$. verticillata and $L$. fortunei, both troublesome non-native invaders in freshwater ecosystems worldwide.

Hydrilla verticillata is similar in morphology with Egeria sp. (Sousa, 2011). This observation might appear to imply that the relationships of these plants to attached invertebrates would not differ. However, $H$. verticillata is more flexible and resistant to flow than the two native species considered in this study (Sousa, 2011). For this reason, it is, most likely, able to support more individuals and biomass of $L$. fortunei without breaking. Indeed, the upper shoots of this species withstand drag forces for a substantially longer time than other submersed species (Zhu et al., 2012). In addition, $H$. verticillata has small teeth on its surface (Langeland, 1996), which make it rough to the touch, whereas Egeria spp. do not have these teeth; surface rugosity may be important in determining the density and size of attached invertebrates (Downes et al., 1998). Thus, the differences that we found can be explained by physical features (in terms of resistance to breakage) together with the higher leaf rugosity of $H$. verticillata. Note that the apparently greater facilitation of $L$. fortunei provided by $H$. verticillata, compared with that provided by native macrophytes, has occurred despite the very recent date of the introduction of $H$. verticillata and the bivalve in Brazil (less than 13 years ago; Sousa, 2011; Belz et al., 2013). Thus, in addition to the physical features, we suspect that the evolutionary history shared by $H$. verticillata and $L$. fortunei may be important to explain our results because both species are native to Asia.

Furthermore, we suppose that other mechanisms (in addition to physical differences) could explain the superior performance of $L$. fortunei in the invasive plant compared with that in the native plants. Mormul et al. (2010b), for example, showed that the assemblages of epiphytic algae in H. verticillata and E. najas differ significantly. According to Lodge (1986), changes in attached microorganisms and organic matter can affect invertebrates. Although individuals of $L$. fortunei are filter-feeding organisms (Sylvester et al., 2005), the differences between the loosely attached algal assemblages colonising $H$. verticillata and $E$. najas (Mormul et al., 2010a), which are potentially used as food 
by the bivalve, could affect the colonisation by bivalves. In addition, there are evidences that the settlement of some bivalves increases in filamentous substrates (Folino-Rorem et al., 2006). Thus, the above factors related with differences in filamentous algae colonizing the macrophytes that we analyzed here could have influenced the higher abundance and especially the larger sizes of $L$. fortunei individuals in $H$. verticillata.

Limnoperna fortunei does not colonise substrates like mud, it needs a relatively consolidated substrate for its establishment (Morton et al., 1973). Hydrilla and Egeria spp. banks may structure habitats, provide adequate colonisation sites and increase the attachment surface for this non-native invasive mussel. Although these species of macrophytes co-occur in several reservoirs in the Paraná River Basin, such as those that we investigated here, their distribution differs in natural habitats. In a floodplain of the Upper Paraná River (located downstream from the reservoirs where we collected our samples), for example, native macrophytes colonise floodplain lakes (Sousa et al., 2010) and are scarce in the river and in its lateral channels (Sousa et al., 2009; Sousa, 2011), where $H$. verticillata attains high densities and biomass (Sousa et al., 2009). Thus, because $H$. verticillata offers a more suitable colonisation site for L. fortunei, as suggested by our results, we suppose that the main river channels and its lateral arms are more prone to bivalve proliferation than natural floodplain lakes, where $H$. verticillata does not grow.

Finally, our results suggest that the arrival of $H$. verticillata in the Paraná basin in 2005 (Sousa, 2011) helped to facilitate the success of $L$. fortunei in this basin. If so, we might have detected at least the first step of an invasional meltdown (Simberloff and Von Holle, 1999) in the ecosystems we studied. We base this inference on the facilitation of the bivalve by the invasive macrophyte and on the superior ability of $L$. fortunei to filter water (Sylvester et al., 2005), leading to cascade effects on the entire ecosystem. However, we emphasise that a full invasional meltdown was not demonstrated in our work and that further studies are necessary to better assess this process.

\section{CONCLUSIONS}

We confirmed our hypothesis that the invasive macrophyte $H$. verticillata enhanced the performance, as suggested by individual attributes, of the invasive bivalve $L$. fortunei. If the facilitation of bivalves by $H$. verticillata is greater than that provided by native macrophytes, as our results indicate, then the invasive macrophyte helps to increase the successful colonisation and spread of the mussel. Further studies of the interaction between these exotic species should incorporate the measurement of dynamic variables, including the growth rates and reproduction of the bivalve.

\section{ACKNOWLEDGMENTS}

We thank Valmir Alves Teixeira and Valdenir Ferreira de Souza for field assistance. We also thank two anonymous reviewers who helped to improve the quality of our work. T.S. Michelan, D.K. Petsch, M.J. Silveira and G.D. Pinha acknowledge the Brazilian Council of Research (CNPq) and the Coordenadoria de Aperfeiçoamento do Pessoal de Nível Superior (CAPES - Brazilian Ministry of Education) for providing scholarships, and S.M. Thomaz is especially thankful to the CNPq for continuous funding through a Research Productivity Grant.

\section{REFERENCES}

Almany GR, 2004. Does increased habitat complexity reduce predation and competition in coral reef fish assemblages? Oikos 106:275-284.

Altieri AH, van Wesenbeeck BK, Bertness MD, Silliman R, 2010. Facilitation cascade drives positive relationship between native biodiversity and invasion success. Ecology 91:1269-1275.

Becker RB, Dettke GA, Montanher DR, 2007. Anatomia de espécies dos gêneros Egeria Planch. e Hydrilla Rich. (Hydrocharitaceae). Rev. Bras. Bioc. 5:360-362.

Belz CE, Darrigran G, Bonel N, Netto OSM, 2010. Density, recruitment, and shell growth of Limnoperna fortunei (Mytilidae), an invasive mussel in tropical South America. J. Freshw. Ecol. 25: 227-233.

Belz CE, Darrigran G, Netto OSM, Boeger WA, Ribeiro Junior PJ, 2012. Analysis of four dispersion vectors in inland waters: the case of the invading bivalves in South America. J. Shellfish Res. 31:777-784.

Burlakova LE, Karatayev AY, Karatayev VA, 2012. Invasive mussels induce community changes by increasing habitat complexity. Hydrobiologia 685:121-134.

Clayton J, Edwards T, 2006. Aquatic plants as environmental indicators of ecological condition in New Zealand lakes. Hydrobiologia 570:147-151.

Cook CKD, Lüönd R, 1982. A revision of the genus Hydrilla (Hydrocharitaceae). Aquat. Bot. 13:485-504.

Darrigran G, Ezcurra de Drago I, 2000. Invasion of the exotic freshwater mussel Limnoperna fortunei (Dunker, 1857) (Bivalvia: Mytilidae) in South America. Nautilus 2:69-73.

Downes BJ, Lake PS, Schreiber ESG, Glaister A, 1998. Habitat structure and regulation of local species diversity in a Stony, Upland Stream. Ecol. Monogr. 68:237-257.

Folino-Rorem N, Stoeckel J, Thorn E, Page L, 2006. Effects of artificial filamentous substrate on zebra mussel (Dreissena polymorpha) settlement. Biol. Invas. 8:89-96.

Green PT, O’Dowd DJ, Abbott KL, Jeffery M, Retallick K, Nally RM, 2011. Invasional meltdown: Invader-invader mutualism facilitates a secondary invasion. Ecology 92:1758-1768.

Jeffries M, 1993. Invertebrate colonization of artificial pondweeds of differing fractal dimension. Oikos 67:142-148.

Karatayev AY, Padilla DK, Minchin D, Boltovskoy D, Burlakova LE, 2007. Changes in global economies and trade: the potential spread of exotic freshwater bivalves. Biol. Invas. 9:161-180.

Klein JC, Verlaque M, 2009. Macrophyte assemblage associated 
with an invasive species exhibiting temporal variability in its development pattern. Hydrobiologia 636:369-378.

Langeland KA, 1996. Hydrilla verticillata (L.F.) Royle (Hydrocharitaceae), "The perfect aquatic weed". Castanea 61:293-304.

Lodge DM, 1986. Selective grazing on periphyton - a determinant of freshwater gastropod microdistributions. Freshwater Biol. 16:831-841.

Mack RN, Von Holle B, Meyerson L, 2007. Assessing the impacts of invasive alien species across multiple spatial scales: the need to work globally and locally. Front. Ecol. Environ. 5:217-220

Madeira PT, Coetzee J A, Center TD, White EE, Tipping PW, 2007. The origin of Hydrilla verticillata recently discovered at a South African dan. Aquat. Bot. 87:176-180.

Mansur MCD, Richinitti LMZ, Santos CP, 1999. [Limnoperna fortunei (Dunker, 1857), molusco bivalve invasor, na bacia do Guaíba, RS, Brasil].[Article in Portuguese]. Biociências 7:147-150.

Mormul RP, Thomaz SM, Higuti J, Martens K, 2010a. Ostracod (Crustacea) colonization of a native and a non-native macrophyte species of Hydrocharitaceae in the Upper Paraná floodplain (Brazil): an experimental evaluation. Hydrobiologia 644:185-193.

Mormul RP, Thomaz SM, Silveira M, Rodrigues L, 2010b. Epiphyton or macrophyte: which primary producer attracts the snail Hebetancylus moricandi? Am. Malacol. Bull. 28:127133.

Morton B, 1973. Some aspects of the biology and functional morphology of the organs, of feeding and digestion of Limnoperna fortunei (Dunker) (Bivalvia: Mytilacea). Malacologia 12:265-281.

Michelan TS, Thomaz SM, Carvalho P, Mormul RP, 2010. Effects of an exotic invasive macrophyte (tropical signalgrass) on native plant community composition, species richness and functional diversity. Freshwater Biol. 55:1315-1326.

Pelicice FM, Agostinho AA, 2006. Feeding ecology of fishes associated with Egeria spp. patches in a tropical reservoir, Brazil. Ecol. Freshw. Fish 15:10-19.

Pinha GD, Aviz D, Lopes Filho DR, Petsch DK, Marchese MR, Takeda AM, 2013. Longitudinal distribution of Chironomidae (Diptera) downstream from a dam in a neotropical river. Braz. J. Biol. 73:549-558.

Ricciardi A, 1998. Global range expansion of the asian mussel Limnoperna fortunei (Mytilidae): another fouling threat to freshwater systems. Biofouling 13:97-106.

Ritchie ME, Olff H, 1999. Spatial scaling laws yield a synthetic theory of biodiversity. Nature 400:557-560.
Rodriguez LF, 2006. Can invasive species facilitate native species? Evidence of how, when, and why these impacts occur. Biol. Inv. 8:927-939.

Sardiña P, Chaves P, Marchese M, 2011. Benthic community responses to invasion by the golden mussel, Limnoperna fortunei Dunker: biotic homogenization vs environmental driving forces. J. N. Am. Benthol. Soc. 30:1009-1023.

Schlaepfer MA, Sax DF, Olden JD, 2011. The potential conservation value of non-native species. Conserv. Biol. 25:428-437.

Simberloff D, Von Holle B, 1999. Positive interactions of nonindigenous species: invasional meltdown? Biol. Invas. $1: 21-32$

Sousa, WTZ, Thomaz SM, Murphy KJ, Silveira MJ, Mormul RP, 2009. Environmental predictors of exotic Hydrilla verticillata L.f. Royle and a native Egeria najas Planch. occurrence in a sub-tropical river floodplain: the upper River Paraná, Brazil. Hydrobiologia 632:65-78.

Sousa WTZ, Thomaz SM, Murhy KJ. 2010. Response of native Egeria najas Planch. and invasive Hydrilla verticillata (L.f.) Role to altered hydroecological regime in a subtropical river. Aquat. Bot. 92:40-48.

Sousa WTZ, 2011. Hydrilla verticillata (Hydrocharitaceae), a recent invader threatening Brazil's freshwater environments: a review of the extent of the problem. Hydrobiologia 669:1-20.

StatSoft Inc., 2007. STATISTICA (data analysis software system), ver. 8.0. Available from: www.statsoft.com

Sylvester F, Dorado J, Boltovskoy D, Juárez A, Cataldo D, 2005. Filtration rates of the invasive pest bivalve Limnoperna fortunei as a function of size and temperature. Hydrobiologia 534:71-80.

Taniguchi H, Tokeshi M, 2004. Effects of habitat complexity on benthic assemblages in a variable environment. Freshwater Biol. 49:1164-1178.

Takeda AM, Mansur MCD, Fujita DS, Bibian JPR, 2003. [Ocorrência da espécie invasora de mexilhão dourado, Limnoperna fortunei (Dunker, 1857), em dois pequenos reservatórios próximos a Curitiba, PR]. [Article in Portuguese]. Acta Biol. Leopoldensia 25:251-254.

Thouvenot L, Haury J, Thiébaut G, 2012. Responses of two invasive macrophyte species to salt. Hydrobiologia 686:213-223.

Vilà M, Espinar Jl, Hejda M, Hulme PE, Jarošík V, Maron JL, Pergl J, Schaffner U, Sun Y, Pyšek P, 2011. Ecological impacts of invasive alien plants: a meta-analysis of their effects on species, communities and ecosystems. Ecol. Lett. 14:702-708.

Zhu G, Li W, Zhang M, Ni L, Wang S, 2012. Adaptation of submerged macrophytes to both water depth and flood intensity as revealed by their mechanical resistance. Hydrobiologia 696:77-93. 